\title{
Article \\ Electrorheological Effect of Gold Nanoparticles Coated with Fluorescent Mesogenic Groups Dispersed in Nematic Liquid Crystal
}

\author{
Kosuke Kaneko ${ }^{1, *(D)}$, Kosuke Yamashita ${ }^{1}$, Daiki Fujioka ${ }^{1}$, Kimiyoshi Kaneko ${ }^{2}$, Kiyomi Fuchigami ${ }^{1,3}$, \\ Takeshi Hashishin ${ }^{4}$ and Tomonori Hanasaki ${ }^{1}$ (I) \\ 1 Department of Applied Chemistry, College of Life Sciences, Ritsumeikan University, 1-1-1 Nojihigashi, \\ Kusatsu 525-8577, Japan; drums.kosuke.b.e.h@gmail.com (K.Y.); d-fuji@fc.ritsumei.ac.jp (D.F.); \\ k-fuchigami@shofu.co.jp (K.F.); hanasaki@sk.ritsumei.ac.jp (T.H.) \\ 2 Research Organization of Science and Technology, Ritsumeikan University, 1-1-1 Nojihigashi, \\ Kusatsu 525-8577, Japan; 17v00193@gst.ritsumei.ac.jp \\ 3 SHOFU Inc., 11 Kamitakamatsu-cho, Fukuine, Higashiyama-ku, Kyoto 605-0983, Japan \\ 4 Faculty of Advanced Science and Technology, Kumamoto University, 2-39-1 Kurokami, Chuo-ku, \\ Kumamoto 860-8555, Japan; hashishin@msre.kumamoto-u.ac.jp \\ * Correspondence: kaneko@fc.ritsumei.ac.jp; Tel.: +81-77-599-3279
}

Citation: Kaneko, K.; Yamashita, K.; Fujioka, D.; Kaneko, K.; Fuchigami, K.; Hashishin, T.; Hanasaki, T.

Electrorheological Effect of Gold Nanoparticles Coated with Fluorescent Mesogenic Groups Dispersed in Nematic Liquid Crystal. Crystals 2021, 11, 192. https:// doi.org/10.3390/cryst11020192

Academic Editor: Shigeyuki Yamada Received: 11 January 2021

Accepted: 11 February 2021

Published: 16 February 2021

Publisher's Note: MDPI stays neutral with regard to jurisdictional claims in published maps and institutional affiliations.

Copyright: (C) 2021 by the authors Licensee MDPI, Basel, Switzerland. This article is an open access article distributed under the terms and conditions of the Creative Commons Attribution (CC BY) license (https:/ / creativecommons.org/licenses/by/ $4.0 /)$
Abstract: The electrorheological (ER) properties of composite materials consisting of a nematic liquid crystal (LC) and gold nanoparticles (GNPs) coated with bistolane-based mesogenic groups were studied. The GNPs were coated by normal alkyl chains and the fluorescent LC compounds, of which the molecular structure was similar to that of the LC matrix. The dispersity of the GNPs in the nematic LC was investigated by polarizing optical microscopy (POM). In order to improve the ER effect of the composite, a simple strategy was investigated from the viewpoint of a material design in surface-modified GNPs by lateral substitution of the mesogenic groups. The presence of the GNPs in the nematic LC led to a slightly enhanced ER effect compared to that observed for only the nematic LC. This study demonstrates the potential of a hybrid system consisting of LCs and GNPs to yield a larger ER effect.

Keywords: liquid crystals; electro rheology; gold nanoparticles; fluorescence

\section{Introduction}

The inclusion of nanoparticles (NPs) within self-organized assemblies such as liquid crystals (LCs) provides unique characteristics with advanced functional properties. In spite of the promising relevance for hybrid systems, fundamental knowledge of the NPs affecting LC properties is still limited, and therefore its development has received increasing attention in recent years [1-10]. Combining the properties of LCs and metallic NPs is applicable to the field of materials science on account of the potential benefits to be derived from exploiting their fused functions.

One of the promising properties of the LC materials is an electrorheological (ER) effect showing controllable viscosity under an electric field. Since the first investigation of the ER effect by Winslow [11], there have been many experimental and theoretical studies of both their fundamental and their practical applications [12-21]. ER fluids are mainly categorized into two types on the basis of the component of the fluids and the mechanism of the effect. One type is the heterogeneous ER fluid, in which the particles with large polarization induced by the external electric field are suspended in insulating oil. The other type is called the homogeneous ER fluid, which is predominantly composed of an organic polar liquid having a spontaneous polarization, such as the LCs. The ER fluids have been found to show great potential in many actuator devices and robotics, such as in brakes, clutches, and dampers in motor vehicles. The magnitude of the electric-field-induced shear 
stresses that are presently achievable is in the order of kilopascals for fields in the order of kilovolts per millimeter. The controllable viscosity changes with fast response times are very useful even in precision control systems that do not require such large changes. However, there are still highly vital problems to be solved for extensive commercial uses of the ER fluids because of the sedimentation of the particles, abrasion of the surface of the plates with the particles from repeating the application, high voltage, slow rise and decay time, and so on.

Integrating and hybridizing both types of ER fluids would lead to new fused materials with higher performance in addition to the intrinsic potential for each to yield generated shear stresses. We previously reported that the composite consisting of a nematic LC (4'-pentyl-4-biphenylcarbonitrile, 5CB) and gold nanoparticles (GNPs) with alkyl chains and mesogenic groups showed a higher enhancement in shear stress under an application of electric fields [22]. In the system, the enhanced shear stress could be accounted for by the assumption that the LC domains show resistance to the shear flow and the particles simultaneously enhance the viscosity change caused by the bridged structure between the electrodes under the applied electric field. Furthermore, the surface modification of the GNPs with the organic components was found to be very important for tuning the miscibility with the LC matrix.

The GNPs should be functionalized to be highly dispersible in host LCs in order to make the fused type of ER fluids. One of the approaches for this strategy is to coat the mesogenic groups onto the NPs [23-36]. Metallic samples are rarely dispersible and miscible to organic materials in general. Directly linking the mesogenic groups through flexible spacers onto the GNPs by a thiol group (-SH) and gold (Au) is a facile method for making the composite materials. Another method is to use a host LC with a chemical structure that is similar to that of the coated mesogenic groups. Similarity of the chemical structures leads to good dispersity, and then the aggregation of the GNPs can be solved. From this perspective, our samples are designed on the basis of a tolane unit, as shown in Figure 1. In the present study, we investigate the ER effect of the GNPs in the nematic LC (4'-((4-heptylphenyl)ethynyl)benzonitrile, 7CT) as a function of shear rate. It is also demonstrated how the GNPs dispersed in the nematic LC behave under the applied electric field by polarizing optical microscope (POM) observations.

(a)

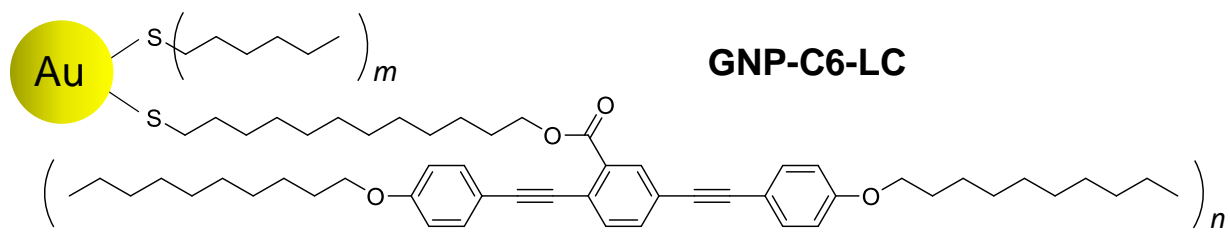

(b)

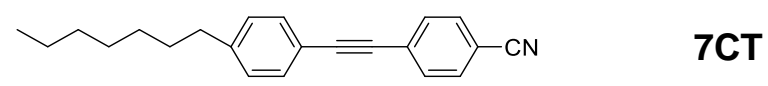

Figure 1. Molecular structures of (a) the liquid crystalline gold nanoparticles (GNP-C6-LC) and (b) the host nematic LC (7CT). The mesogenic groups in GNP-C6-LC were connected by "sideon" attachment.

\section{Materials and Methods}

\subsection{Materials}

1-Bromodecane, 4-bromophenol, trimethylsilylacetylene, 2,5-dibromobenzoic acid, 12-bromo-1-dodecanol, bis(trimethylsilyl) sulfide, 1-hexanethiol, hydrogen tetrachloroaurate(III) tetrahydrate, 1-bromo-4-heptylbenzene, and 4-bromobenzonitrile were purchased from Tokyo Kasei Kogyo Co., Ltd. (Tokyo, Japan). All of the solvents used in this study were used without further purification. 


\subsection{Characterization}

${ }^{1} \mathrm{H}$ NMR spectra were recorded on an ECS 400 NMR spectrometer (JEOL, Tokyo, Japan) at $400 \mathrm{MHz}$, using $\mathrm{CDCl}_{3}$ as the solvent. Chemical shifts ( $\delta$ ) are expressed in ppm relative to tetramethylsilane (TMS, $\delta=0.0 \mathrm{ppm}$ ) as an internal standard. Thermal properties were measured by differential scanning calorimetry (DSC) using a Diamond DSC (PerkinElmer, Kanagawa, Japan) with heating and cooling rates of $5{ }^{\circ} \mathrm{C} \mathrm{min}^{-1}$. The textures of the LC phases were observed with an ECLIPSE E600 polarizing optical microscope (POM) (Nikon, Tokyo, Japan) equipped with a FP-82 hot stage and a FP-90 central processor (Mettler-Toledo, Tokyo, Japan). Transmission electron microscopy (TEM) for the particle size analysis was conducted with JEM-2010 (JEOL, Tokyo, Japan) operating at $200 \mathrm{kV}$. The thermogravimetry (TG) analysis was performed by DTG-60AH (Shimadzu, Tokyo, Japan).

\subsection{Rheological Measurements}

The rheological properties were measured on a rotational rheometer (Rheosol-G2000, UBM, Japan) equipped with an electric-field controller (PSK20P-5, Matsusada Precision, Kyoto, Japan). All the measurements were performed using $15 \mathrm{~mm}$ diameter parallel plates and a $0.1 \mathrm{~mm}$ gap. The sample was first mounted between the parallel plates, heated to the isotropic state, and held at this temperature for $10 \mathrm{~min}$. It was then allowed to cool to the measuring temperature and allowed to equilibrate for $10 \mathrm{~min}$. An electric field of $3 \mathrm{kV} \mathrm{mm}{ }^{-1}$ was applied between the upper and lower plates under steady shear flow and constant shear rate. The generated shear stress was defined as the difference between the shear stress measured in the presence and absence of the electric field.

\section{Results and Discussion}

\subsection{Phase Behavior}

The synthetic route of the thiol compound (Thiol LC) used for coating the GNPs is shown in Figure S1. In the synthetic process of Thiol LC, we checked whether a disulfide with an -S-S- bonding, which is obtained by the coupling of the two thiol groups, was formed as a by-product. In the ${ }^{1} \mathrm{H}$ NMR spectrum of Thiol LC (Figure S2), the quartet signal assigned to the protons of the $\alpha$-carbon was observed at $2.51 \mathrm{ppm}\left(-\mathrm{CH}_{2}-\mathrm{CH}_{2}-\mathrm{SH}\right)$. This result evidently supports that the desired thiol compound was obtained without the by-product. In addition, we confirmed that the quartet signal changed to a triplet signal by mixing with $\mathrm{D}_{2} \mathrm{O}\left(-\mathrm{CH}_{2}-\mathrm{CH}_{2}-\mathrm{SD}\right)$. This behavior indicates that the thiol group at the terminal part of the side-on spacer was exchanged with an -SD group.

The phase transition behavior of Thiol LC was studied by DSC and POM observations. The thiol compound exhibited a Schlieren texture in a wide temperature range from -33 to $74{ }^{\circ} \mathrm{C}$ on heating (scanning rate: $5{ }^{\circ} \mathrm{C} \mathrm{min}-1$ ), as shown in Figure 2. In the DSC diagram in Figure 2a, an endothermic peak was detected at $74{ }^{\circ} \mathrm{C}$. This temperature is in good agreement with that at which the texture disappeared in the POM observation on heating. This result was related to the appearance of the nematic phase, and the endothermic peak corresponds to the clearing point $(\mathrm{Tcl})$. 

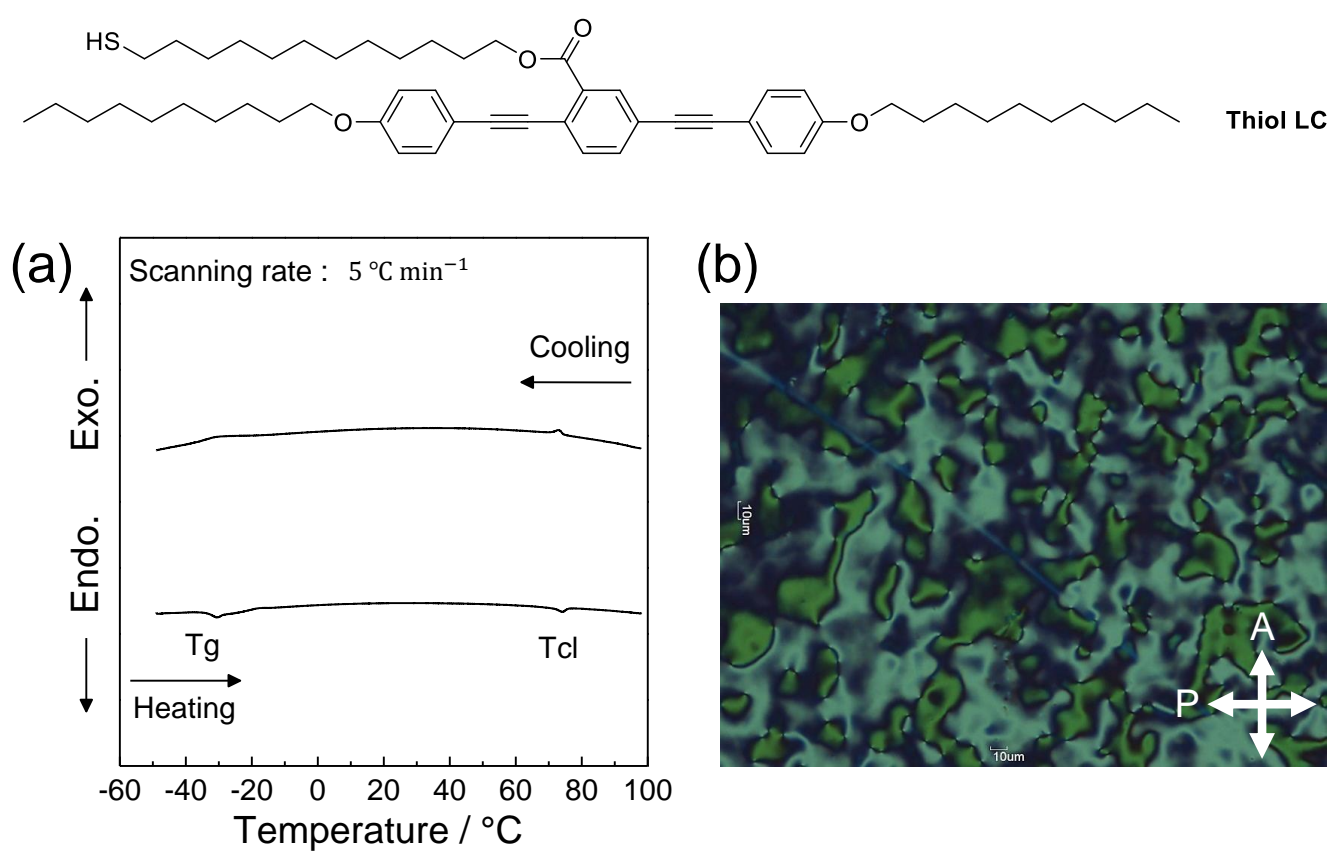

Figure 2. (a) Differential scanning calorimetry (DSC) curves and (b) polarizing optical microscopy (POM) image of the thiol LC (Thiol LC). The image was taken at $65^{\circ} \mathrm{C}$ on cooling.

\subsection{Characterization of the GNPs}

The GNPs covered by normal alkyl chains (1-hexanethiol) and the LC thiol compounds were characterized by ${ }^{1} \mathrm{H}$ NMR spectroscopy. The broadening of the peaks is one of the forms of evidence for the coverage of the GNPs by the alkyl chains and the LC thiol compounds. In addition, the respective signals assigned to the protons of the $\alpha$-carbons were shifted downfield after the coating on the GNPs (Figure S6). Figure S7 shows the ${ }^{1} \mathrm{H}$ NMR spectrum of GNP-C6-LC enlarged in a range from $5.0 \mathrm{ppm}$ to $-0.5 \mathrm{ppm}$. By comparing the peak area of the signals at 4.0-3.8 ppm and 0.9-0.7 ppm, we estimated the coverage ratio between 1-hexanethiol and Thiol LC. As a result of the calculation, the coverage ratio was found to be about 1:2 =1-hexanethiol: Thiol LC. Details of the synthetic process are referred to in our previous paper [22].

A high-resolution transmission electron microscopy (HR-TEM) image of GNP-C6-LC and the particle size distribution is shown in Figure 3. The results showed a monodispersed distribution in particles size ranging from 5 to $35 \mathrm{~nm}$, and the average diameter was determined to be $16.1 \mathrm{~nm}$ with standard deviation $\sigma=4.75 \mathrm{~nm}$.

(a)

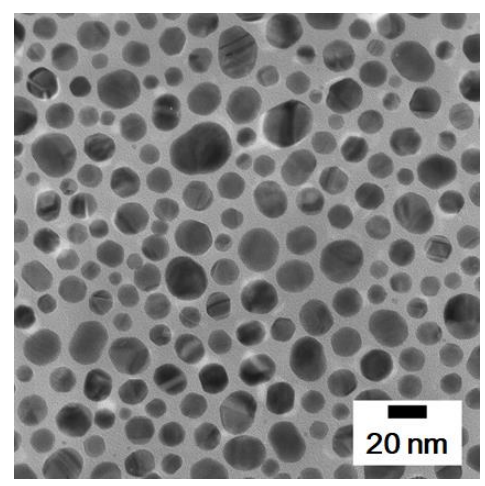

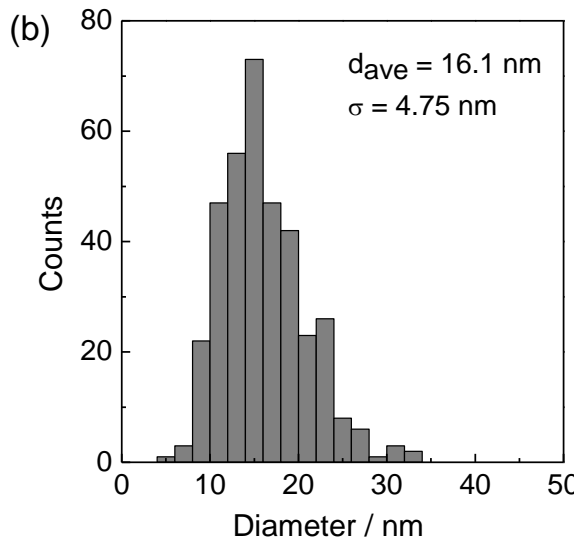

Figure 3. (a) TEM image and (b) the particle size histogram of GNP-C6-LC. 
The total amount of the pendant alkyl chains and LC moieties acting as a capping agent for GNPs were investigated by TG analysis in the atmosphere air. The TG curves of GNP-C6 and GNP-C6-LC are shown in Figure 4. As illustrated in the figure, the weights of both samples started to decrease at around $140{ }^{\circ} \mathrm{C}$, which corresponds to the decomposition of the organic compounds coated on the surface of the GNPs. A weight loss of 36\% for GNPC6 coated with only alkyl chains and 54\% for GNP-C6-LC was observed in the temperature region ranging from $50{ }^{\circ} \mathrm{C}$ to $600{ }^{\circ} \mathrm{C}$. The initial weight loss from $150{ }^{\circ} \mathrm{C}$ to $200{ }^{\circ} \mathrm{C}$ was due to the decomposition of the alkyl chains attached to the GNPs. In the temperature region between $350^{\circ} \mathrm{C}$ and $500{ }^{\circ} \mathrm{C}$, the next dominant weight loss for GNP-C6-LC was recorded, which is obviously different for GNP-C6. This trend is due to the gradual decomposition of the LC pendants and the alkyl spacer connecting between the mesogenic core and the GNPs. The different behavior in the TG analysis confirms that the thiol LC was surely coated on the GNPs in addition to the normal alkyl chains.

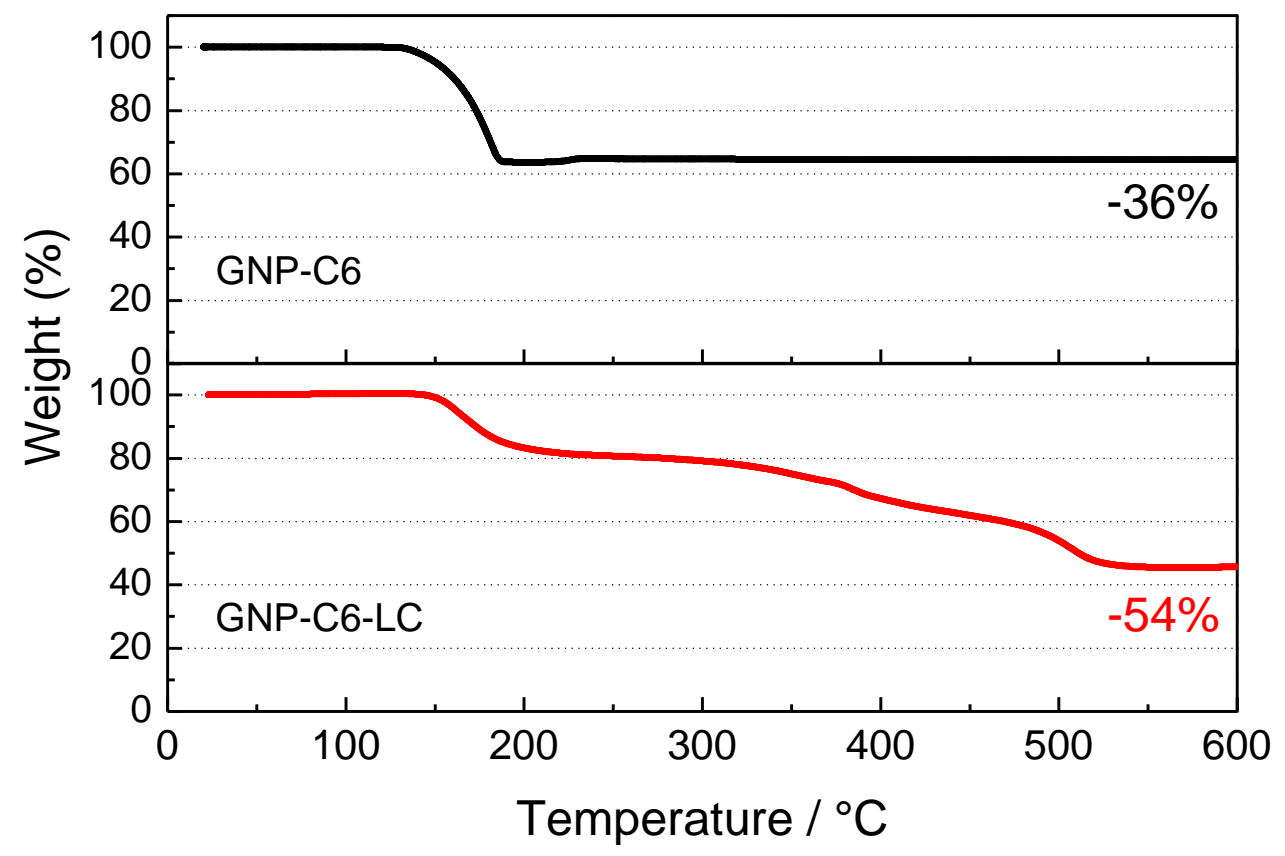

Figure 4. TG curves of GNP-C6 and GNP-C6-LC.

In order to further characterize GNP-C6-LC, the photo-physical properties of GNP-C6LC were examined in comparison to those of the thiol LC. Bistolane-based LCs have been known to be promising light-emitting (LE) materials. Yamada et al. intensely investigated the families of bistolane-based LCs, which are categorized as light-emitting liquid crystals (LELCs) [37-40]. Herein, the absorption and photoluminescence (PL) behavior of Thiol LC and GNP-C6-LC in dilute $\mathrm{CH}_{2} \mathrm{Cl}_{2}$ solutions (approximately $1.0 \times 10^{-6} \mathrm{M}$ ) was studied. It should be strongly noted that GNP-C6-LC is well dispersed in the organic solvent without aggregating. The improved dispersibility for GNP-C6-LC is attributed by the surface coating with the organic compounds. The absorption and PL spectra obtained for Thiol LC and GNP-C6-LC are shown in Figure 5a. The thiol LC showed an absorption band with a maximum absorption wavelength $\left(\lambda_{\mathrm{abs}}\right)$ at $354 \mathrm{~nm}$, with the shoulders at $330 \mathrm{~nm}$ and $250 \mathrm{~nm}$. Under excitation light $\left(\lambda_{\mathrm{ex}}=356 \mathrm{~nm}\right)$, it exhibited a single PL band with a maximum PL wavelength of $409 \mathrm{~nm}$. For GNP-C6-LC, a similar absorption and PL spectra were observed, resulting from the surface coating by the thiol LCs. Figure $5 \mathrm{~b}$ shows the $\mathrm{CH}_{2} \mathrm{Cl}_{2}$ solution of GNP-C6-LC emitting blue PL under UV light. 
(a)

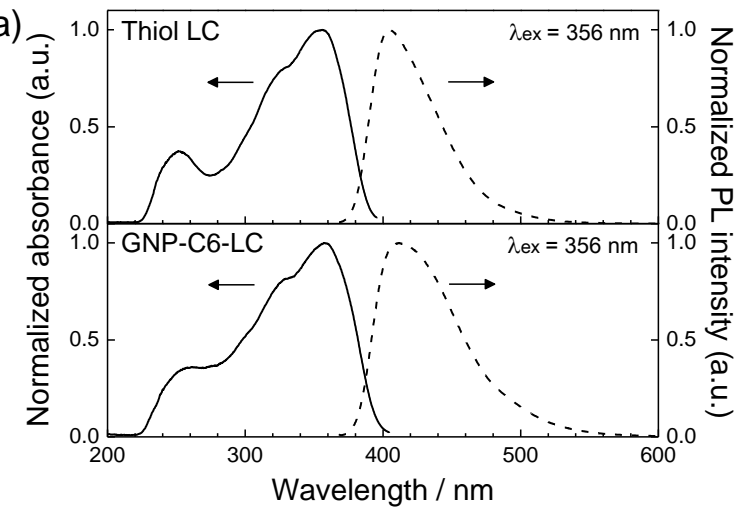

(b)

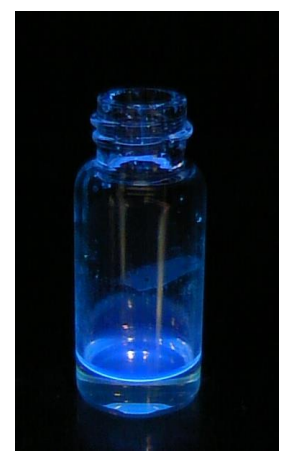

Figure 5. (a) Normalized absorbance (solid line) and emission spectra (dashed line) of the thiol LC and GNP-C6-LC in $\mathrm{CH}_{2} \mathrm{Cl}_{2}\left(1.0 \times 10^{-6} \mathrm{M}\right)$ and $(\mathbf{b})$ the $\mathrm{CH}_{2} \mathrm{Cl}_{2}$ solution of GNP-C6-LC under UV light.

\subsection{Phase Behavior of the Composites}

We prepared the composites consisting of 7CT and GNP-C6-LC $(5,10 \mathrm{wt} \%)$, and their phase transition behavior was investigated by DSC and POM observations. Figure 6 shows the DSC curves and the POM images of pure 7CT and the composites. In the heating process, the melting points (Tm) and the clearing points (Tcl) decreased slightly as the concentration of GNP-C6-LC increased, and the temperature range of the LC phase ( $\triangle \mathrm{TLC}$ ) also narrowed slightly $(0 \%: \Delta \mathrm{TLC}=8.0 \mathrm{~K}, 5 \%: \Delta \mathrm{TLC}=7.5 \mathrm{~K}, 10 \%: \Delta \mathrm{TLC}=6.7 \mathrm{~K})$. In addition, the temperatures at which the nematic phase appeared on cooling also decreased with the increasing concentration of GNP-C6-LC $\left(0 \%: 64.3{ }^{\circ} \mathrm{C}, 5 \%: 62.0^{\circ} \mathrm{C}, 10 \%: 59.9{ }^{\circ} \mathrm{C}\right)$. These results suggest that the inclusion of particles hindered the orientation of the 7CT molecules and consequently destabilized the LC phase. On the basis of the results obtained here, we decided to measure rheological properties at $58{ }^{\circ} \mathrm{C}$ in the nematic phase. For the composite with a higher concentration of GNPs (more than 10\%), the macroscopic aggregation of GNP-C6-LC was obtained, and therefore no further investigation was performed because of the danger of a leak current under a high electric field.

(a)

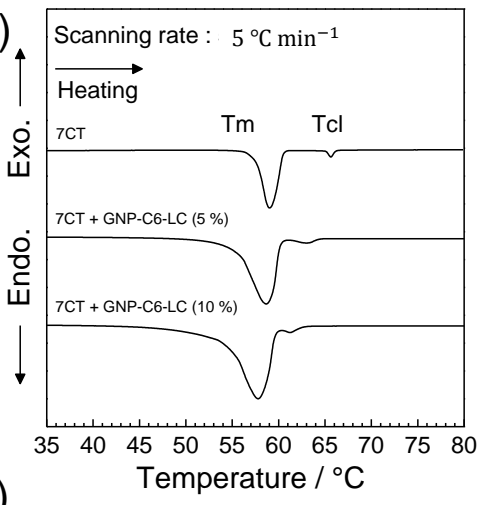

(c)

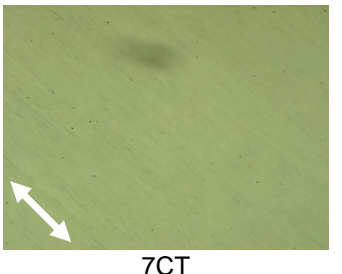

(b)

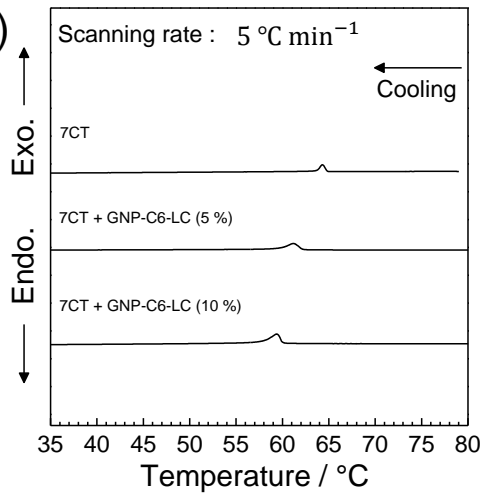

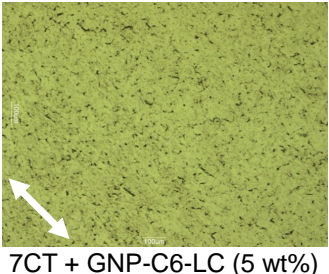

7CT + GNP-C6-LC (5 wt\%)

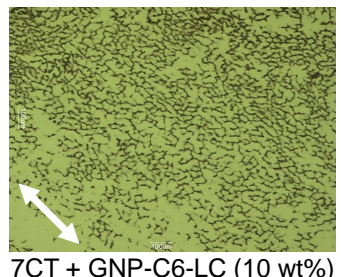

7CT + GNP-C6-LC (10 wt\%)

Figure 6. DSC curves on (a) heating and (b) cooling, and (c) open Nicol images in the homogeneous cells (white arrow: rubbing direction) of 7CT and the composites consisting of 7CT and GNP-C6-LC $(5,10 w t \%)$. 


\subsection{Electrorheological Property}

The rheological response of the composite was investigated by steady shear experiments at a constant shear rate of $100 \mathrm{~s}^{-1}$ under the electric field. An electric field of $3 \mathrm{kV} \mathrm{mm}^{-1}$ was repeatedly applied to the composite at intervals of $100 \mathrm{~s}$. The rheological results for 7CT and the composite (GNP-C6-LC $(5,10 \mathrm{wt} \%$ ) in 7CT) are shown in Figure 7. The steady states were obtained without the electric field for all the samples, where the shear stress of the composites was slightly higher than that of 7CT by the addition of GNPC6-LC. The shear stress of the samples immediately increased just after the application of the electric field at $100 \mathrm{~s}$. Subsequently, a quick decrease in the shear stress was observed after the removal of the electric field, indicating that the organized structures relaxed to their initial state. The reversible ER response was demonstrated by the rapid change of the shear stress upon the application and removal of the electric field. In addition, the stable repeatability of the ER effect was confirmed in the multiple cycles of the ER response. On the basis of the results obtained, it can be concluded that the generated shear stress in the composites was slightly enhanced by the addition of GNP-C6-LC.

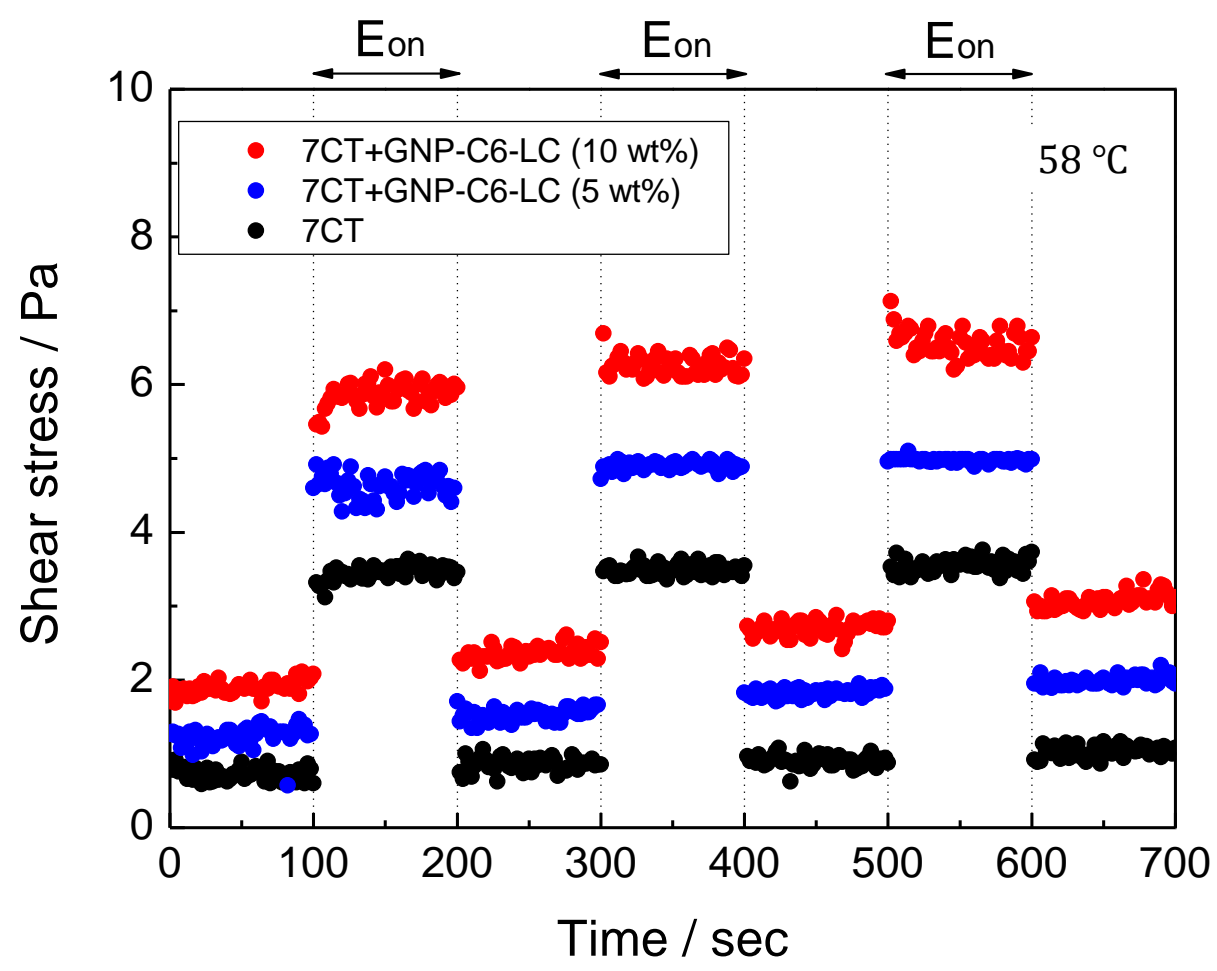

Figure 7. Electrorheological (ER) responses of 7CT and the composite (GNP-C6-LC $(5,10 \mathrm{wt} \%)$ in 7CT) under $3 \mathrm{kV} \mathrm{mm}^{-1}$.

The dependence of the shear rate on the shear stress of the composite $(10 \mathrm{wt} \%)$ at $58^{\circ} \mathrm{C}$ is shown in Figure 8. With regard to the measuring method, it should be noted that the shear stress was measured by increasing the shear rate stepwise from 0 to $100 \mathrm{~s}^{-1}$. As shown in Figure 8, the shear stresses increased roughly in proportion to the shear rate under 0 and $3 \mathrm{kV} \mathrm{mm}^{-1}$, which is known as Newtonian behavior. This mainly resulted from the reorientation of 7CT with a positive dielectric anisotropy, which is a characteristic of homogeneous ER fluids. On the other hand, Bingham behavior is generally observed in heterogeneous ER fluids, in which a viscosity change occurs owing to the crosslinked structure of the particles between the two parallel plates under the electric field. This observed behavior might be caused by the fact that the particle size of GNP-C6LC contained in the composite is extremely small, and the crosslinked structure is easily destroyed by the Brownian motion of the 7CT molecules. 


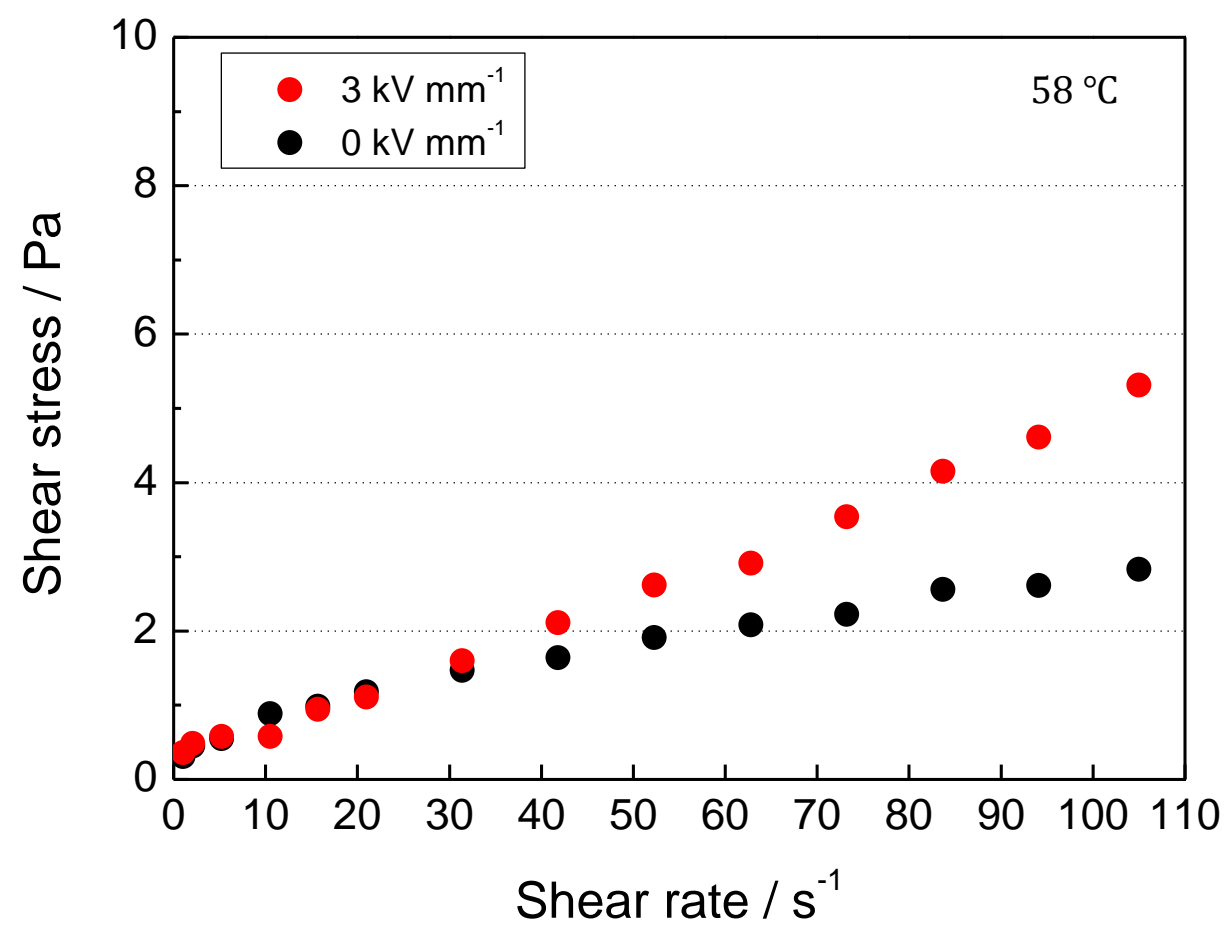

Figure 8. Shear stress as a function of shear rate of the composite (GNP-C6-LC (10 wt\%) in 7CT) under 0 and $3 \mathrm{kV} \mathrm{mm}^{-1}$.

\subsection{POM Observation under an Applied Electric Field}

The compositional homogeneity of the produced composite represents an important step towards the application of LC-based ER fluid devices. The miscibility of GNP-C6-LC to 7CT was accurately evaluated by the POM observation. Optical investigations of the composite under an applied electric field were carried out in a transparent sandwich-type cell consisting of two glass plates coated with indium tin oxide (ITO) and treated for a homogeneous alignment. The composite was induced into the cell at the isotropic state and then cooled to the temperature at which the ER measurement was performed in the nematic phase $\left(58{ }^{\circ} \mathrm{C}\right)$. The POM images of the composite (GNP-C6-LC $(10 \mathrm{wt} \%)$ in $\left.7 \mathrm{CT}\right)$ are shown in Figure 9a-d. First, the 7CT molecules were found to be certainly aligned in the rubbing direction, confirmed by the fact that a uniformly colored (dark brown) image was observed, as shown in Figure 9a. A small aggregation of GNP-C6-LC across the whole of 7CT was also clearly observed. Next, the alignment behavior of the composite was observed when an electric field was applied. As shown in Figure 9b, the POM image turned mostly dark upon the application of the electric field perpendicular to the ITO surface. This implies that the 7CT molecules were homeotropically aligned along the direction of the electric field. Thus, the reorientation of $7 \mathrm{CT}$ by the electric field was unaffected by the small aggregation of GNP-C6-LC.

Subsequently, in order to confirm the behavior of GNP-C6-LC under an electric field, the POM observation was conducted under open Nicol. The open Nicol images of the composite under 0 and $3 \mathrm{kV} \mathrm{mm}^{-1}$ can be observed in Figure $9 \mathrm{c}, \mathrm{d}$, respectively. As can be seen from the figures, the composite had a small aggregation in the absence of an electric field, but the change in the image occurred after the application of the electric field. This behavior might be indicative of the crosslinked structure or the reformed aggregation of the GNPs. However, as mentioned above, the composite (GNP-C6-LC (10 wt\%) in 7CT) demonstrated Newtonian behavior, as confirmed in Figure 8. From the results of the POM observation and the ER measurements, it could be concluded that the crosslinked structure of the GNPs was weak enough to result in the higher viscosity and rarely played an effective role in the enhanced ER effect. 

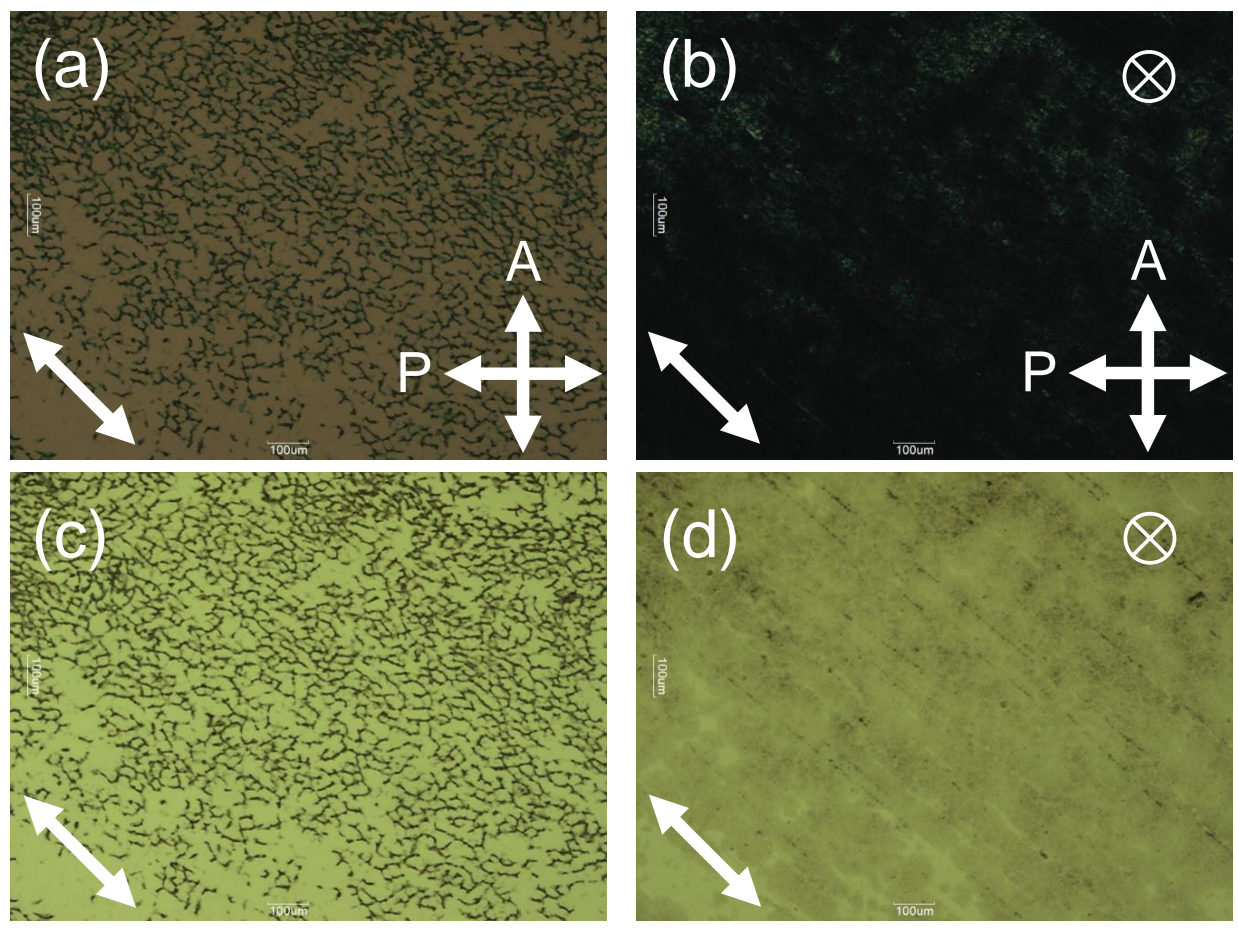

Figure 9. (a,b) Cross Nicol and (c,d) open Nicol images of GNP-C6-LC (10 wt\%) in $7 \mathrm{CT}$ at $58{ }^{\circ} \mathrm{C}$. The images were taken under $(\mathbf{a}, \mathbf{c}) 0 \mathrm{kV} \mathrm{mm}^{-1}$ and $(\mathbf{b}, \mathbf{d}) 3 \mathrm{kV} \mathrm{mm}^{-1}$.

\section{Conclusions}

In summary, we presented the fabrication of surface-functionalized GNPs and the ER effect of the composite consisting of the GNPs and the nematic LC. By adding the surface-functionalized GNPs into 7CT, a slightly enhanced change in the shear stress for the LC composites was observed compared with that observed for only 7CT. Our approach in which the mesogenic groups were coated onto the GNPs successfully provided dispersible metallic particles in the LC matrix and resulted in a fusional ER system via the organic/inorganic materials. In addition, we succeeded in producing fluorescent GNPs capable of dispersing in the organic solvent. Further investigation of the ER properties of such hybrid ER fluids is necessary for yielding larger viscosity changes and expanding upon the new insights obtained in this study.

Supplementary Materials: The following are available online at https:/ /www.mdpi.com/2073-435 2/11/2/192/s1: Figure S1: Synthetic route of the thiol LC used for coating the GNPs. Figure S2: ${ }^{1} \mathrm{H}$ NMR spectrum of Thiol LC. Figure S3: Synthetic route of the host nematic LC (7CT). Figure S4: ${ }^{1} \mathrm{H}$ NMR spectrum of 7CT. Figure S5: (a) DSC curves and (b) POM image of 7CT. The image was taken at $63{ }^{\circ} \mathrm{C}$ on cooling. Figure S6: ${ }^{1} \mathrm{H}$ NMR spectra of (a) 1-hexanethiol and GNP-C6, and (b) Thiol LC and GNP-C6-LC. Figure S7: ${ }^{1} \mathrm{H}$ NMR spectrum of GNP-C6-LC. Figure S8: DSC curves of the composites consisting of 7CT and GNP-C6-LC ((a) $5 \mathrm{wt} \%$ and (b) $10 \mathrm{wt} \%)$.

Author Contributions: Conceptualization: K.K. (Kosuke Kaneko); methodology: K.Y. and D.F.; formal analysis: K.Y., D.F., K.K. (Kimiyoshi Kaneko), K.F., and T.H. (Takeshi Hashishin); investigation: K.Y., D.F., K.K. (Kimiyoshi Kaneko), K.F., and T.H. (Takeshi Hashishin); writing-original draft preparation: K.K. (Kosuke Kaneko); writing—review and editing: K.K. (Kosuke Kaneko) and D.F.; project administration:T.H. (Tomonori Hanasaki). All authors have read and agreed to the published version of the manuscript.

Funding: This research received no external funding.

Acknowledgments: This research was partially supported by the Program for the International Dissemination of Research Results (2020) of Ritsumeikan University.

Conflicts of Interest: The authors declare no conflict of interest. 


\section{References}

1. Baginski, M.; Tupikowska, M.; Gonzalez-Rubio, G.; Wojcik, M.; Lewandowski, W. Shaping Liquid Crystals with Gold Nanoparticles: Helical Assemblies with Tunable and Hierarchical Structures via Thin-Film Cooperative Interactions. Adv. Mater. 2020, 32, 1904581. [CrossRef] [PubMed]

2. Wang, Y.; Dang, A.; Zhang, Z.; Yin, R.; Gao, Y.; Feng, L.; Yang, S. Repeatable and Reprogrammable Shape Morphing from Photoresponsive Gold Nanorod/Liquid Crystal Elastomers. Adv. Mater. 2020, 32, 2004270. [CrossRef]

3. Shivaraja, S.J.; Gupta, R.K.; Kumar, S.; Manjuladevi, V. Enhanced electro-optical response of nematic liquid crystal doped with functionalised silver nanoparticles in twisted nematic configuration. Liq. Cryst. 2020, 47, 1678-1690.

4. Hu, J.; Kuang, Z.-Y.; Tao, L.; Huang, Y.-F.; Wang, Q.; Xie, H.-L.; Yin, J.-R.; Chen, E.-Q. Programmable 3D Shape-Change Liquid Crystalline Elastomer Based on a Vertically Aligned Monodomain with Cross-link Gradient. ACS Appl. Mater. Interfaces 2019, 11, 48393-48401. [CrossRef]

5. $\quad$ Lesiak, P.; Bednarska, K.; Lewandowski, W.; Wojcik, M.; Polakiewicz, S.; Baginski, M.; Osuch, T.; Markowski, K.; Orzechowski, K.; Makowski, M.; et al. Self-organized, one-dimensional periodic structures in gold nanoparticle-doped nematic liquid crystal composite. ACS Nano 2019, 13, 10154-10160. [CrossRef] [PubMed]

6. Xu, J.; Chen, S.; Yang, W.; Qin, B.; Wang, X.; Wang, Y.; Cao, M.; Gao, Y.; Li, C.; Dong, Y. Photo actuation of liquid crystalline elastomer nanocomposites incorporated with gold nanoparticles based on surface plasmon resonance. Soft Matter 2019, 15, 6116-6126. [CrossRef] [PubMed]

7. Mangaiyarkarasi, R.; Sivaranjini, B.; Umadevi, S. Facile synthesis of gold nanoparticles capped with an ammonium-based chiral ionic liquid crystal. Liq. Cryst. 2019, 46, 584-593. [CrossRef]

8. Das, N.; Borah, D.; Acharya, H.; Choudhury, S.; Prasad, S.K.; Rao, D.S.S.; Bhattacharjee, C.R. Grafting a mesomorphic Schiff base onto gold nanoparticle via ester link-Photoluminescence, mesomorphism, electrical conductivity and antioxidant activity. Liq. Cryst. 2019, 46, 609-617. [CrossRef]

9. Nemati, A.; Shadpour, S.; Querciagrossa, L.; Li, L.; Mori, T.; Gao, M.; Zannoni, C.; Hegmann, T. Chirality amplification by desymmetrization of chiral ligand-capped nanoparticles to nanorods quantified in soft condensed matter. Nat. Commun. 2018, 9, 1-13. [CrossRef]

10. Cseh, L.; Mang, X.; Zeng, X.; Liu, F.; Mehl, G.H.; Ungar, G.; Siligardi, G. Helically Twisted Chiral Arrays of Gold Nanoparticles Coated with a Cholesterol Mesogen. J. Am. Chem. Soc. 2015, 137, 12736-12739. [CrossRef]

11. Winslow, W.M. Induced Fibration of Suspensions. J. Appl. Phys. 1949, 20, 1137-1140. [CrossRef]

12. Inoue, A.; Maniwa, S. Electrorheological effect of liquid crystalline polymers. J. Appl. Polym. Sci. 1995, 55, 113-118. [CrossRef]

13. Inoue, A.; Ide, Y.; Oda, H. Influence of dilution by polydimethylsiloxane on electrorheological effect of side-chain liquid crystalline polysiloxane. J. Appl. Polym. Sci. 1997, 64, 1319-1328. [CrossRef]

14. Inoue, A.; Maniwa, S.; Ide, Y. Relation between molecular structure and electrorheological effects in liquid crystalline polymers. J. Appl. Polym. Sci. 1997, 64, 303-310. [CrossRef]

15. Tanaka, K.; Oiwa, Y.; Akiyama, R.; Kubono, A. Shear Thinning and Electro-Rheological Effect for Neat Liquid Crystalline Polysiloxane in the Vicinity of Isotropic-Liquid Crystalline Phase Transition. Polym. J. 1998, 30, 171-176. [CrossRef]

16. Orihara, H.; Kawasaki, T.; Doi, M.; Inoue, A. Immiscible polymer blend electrorheological fluids: Composition dependence. J. Appl. Polym. Sci. 2002, 86, 3673-3680. [CrossRef]

17. Mimura, K.; Nishimoto, Y.; Orihara, H.; Moriya, M.; Sakamoto, W.; Yogo, T. Synthesis of Transparent and Field-Responsive $\mathrm{BaTiO}_{3}$ Particle/Organosiloxane Hybrid Fluid. Angew. Chem. Int. Ed. 2010, 49, 4902-4906. [CrossRef]

18. Kaneko, K.; Kawai, T.; Nakamura, N. Electrorheological Effect of "Side-on" Liquid Crystalline Polysiloxane. ChemPhysChem 2008, 9, 2457-2460. [CrossRef] [PubMed]

19. Kaneko, K.; Mandai, A.; Heinrich, B.; Donnio, B.; Hanasaki, T. Electric Field-Induced Reversible Viscosity Change in Columnar Liquid Crystal. ChemPhysChem 2010, 11, 3596-3598. [CrossRef] [PubMed]

20. Hanasaki, T.; Kamei, Y.; Mandai, A.; Uno, K.; Kaneko, K. Phase Transition Behavior and Electro-Rheological Effect of Liquid Crystalline Siloxane Dimers. Liq. Cryst. 2011, 38, 841-848. [CrossRef]

21. Kaneko, K.; Oto, K.; Kawai, T.; Choi, H.; Kikuchi, H.; Nakamura, N. Electro-Rheological Effect and Electro-Optical Properties of Side-on Liquid Crystalline Polysiloxane in a Nematic Solvent. ChemPhysChem 2013, 14, 2704-2710. [CrossRef] [PubMed]

22. Kaneko, K.; Ujihara, Y.; Oto, K.; Hashishin, T.; Hanasaki, T. Electric-Field-Induced Viscosity Change of a Nematic Liquid Crystal with Gold Nanoparticles. ChemPhysChem 2015, 16, 919-922. [CrossRef] [PubMed]

23. Cseh, L.; Mehl, G.H. The Design and Investigation of Room Temperature Thermotropic Nematic Gold Nanoparticles. J. Am. Chem. Soc. 2006, 128, 13376-13377. [CrossRef]

24. Cseh, L.; Mehl, G.H. Structure-property relationships in nematic gold nanoparticles. J. Mater. Chem. 2007, 17, 311-315. [CrossRef]

25. Zeng, X.; Liu, F.; Fowler, A.G.; Ungar, G.; Cseh, L.; Mehl, G.H.; Macdonald, J.E. 3D Ordered Gold Strings by Coating Nanoparticles with Mesogens. Adv. Mater. 2009, 21, 1746-1750. [CrossRef]

26. Kanayama, N.; Tsutsumi, O.; Kanazawa, A.; Ikeda, T. Distinct thermodynamic behaviour of a mesomorphic gold nanoparticle covered with a liquid-crystalline compound. Chem. Commun. 2001, 24, 2640-2641. [CrossRef]

27. Qi, H.; Hegmann, T. Formation of periodic stripe patterns in nematic liquid crystals doped with functionalized gold nanoparticles. J. Mater. Chem. 2006, 16, 4197-4205. [CrossRef] 
28. Donnio, B.; García-Vázquez, P.; Gallani, J.-L.; Guillon, D.; Terazzi, E. Dendronized Ferromagnetic Gold Nanoparticles SelfOrganized in a Thermotropic Cubic Phase. Adv. Mater. 2007, 19, 3534-3539. [CrossRef]

29. Marx, V.M.; Girgis, H.; Heiney, P.A.; Hegmann, T. Bent-core liquid crystal (LC) decorated gold nanoclusters: Synthesis, selfassembly, and effects in mixtures with bent-core LC hosts. J. Mater. Chem. 2008, 18, 2983-2994. [CrossRef]

30. Qi, H.; Kinkead, B.; Hegmann, T. Unprecedented Dual Alignment Mode and Freedericksz Transition in Planar Nematic Liquid Crystal Cells Doped with Gold Nanoclusters. Adv. Funct. Mater. 2008, 18, 212-221. [CrossRef]

31. Qi, H.; Kinkead, B.; Marx, V.M.; Kinkead, B.; Zhang, H.R.; Kinkead, B.; Hegmann, T. Miscibility and Alignment Effects of Mixed Monolayer Cyanobiphenyl Liquid-Crystal-Capped Gold Nanoparticles in Nematic Cyanobiphenyl Liquid Crystal Hosts. ChemPhysChem 2009, 10, 1211-1218. [CrossRef] [PubMed]

32. Wojcik, M.; Lewandowski, W.; Matraszek, J.; Mieczkowski, J.; Borysiuk, J.; Pociecha, D.; Gorecka, E. Liquid-Crystalline Phases Made of Gold Nanoparticles. Angew. Chem. Int. Ed. 2009, 48, 5167-5169. [CrossRef]

33. Wojcik, M.; Kolpaczynska, M.; Pociecha, D.; Mieczkowski, J.; Gorecka, E. Multidimensional structures made by gold nanoparticles with shape-adaptive grafting layers. Soft Matter 2010, 6, 5397-5400. [CrossRef]

34. Draper, M.; Saez, I.M.; Cowling, S.J.; Gai, P.; Heinrich, B.; Donnio, B.; Guillon, D.; Goodby, J.W. Self-Assembly and Shape Morphology of Liquid Crystalline Gold Metamaterials. Adv. Funct. Mater. 2011, 21, 1260-1278. [CrossRef]

35. Nealon, G.L.; Greget, R.; Dominguez, C.; Nagy, Z.T.; Guillon, D.; Gallani, J.-L.; Donnio, B. Liquid-crystalline nanoparticles: Hybrid design and mesophase structures. Beilstein J. Org. Chem. 2012, 8, 349-370. [CrossRef]

36. Mischler, S.; Guerra, S.; Deschenaux, R. Design of liquid-crystalline gold nanoparticles by click chemistry. Chem. Commun. 2012, 48, 2183-2185. [CrossRef]

37. Yamada, S.; Mitsuda, A.; Miyano, K.; Tanaka, T.; Morita, M.; Agou, T.; Kubota, T.; Konno, T. Development of novel solid-state light-emitting materials based on pentafluorinated tolane fluorophores. ACS Omega 2018, 3, 9105-9113. [CrossRef] [PubMed]

38. Yamada, S.; Morita, M.; Agou, T.; Kubota, T.; Ichikawa, T.; Konno, T. Thermoresponsive luminescence properties of polyfluorinated bistolane-type light-emitting liquid crystals. Org. Biomol. Chem. 2018, 16, 5609-5617. [CrossRef] [PubMed]

39. Yamada, S.; Miyano, K.; Konno, T.; Agou, T.; Kubota, T.; Hosokai, T. Fluorine-containing bistolanes as light-emitting liquid crystalline molecules. Org. Biomol. Chem. 2017, 15, 5949-5958. [CrossRef]

40. Yamada, S.; Morita, M.; Konno, T. Multi-color photoluminescence induced by electron-density distribution of fluorinated bistolane derivatives. J. Fluorine Chem. 2017, 202, 54-64. [CrossRef] 